\title{
Effects of Ethanol Addition on the Efficiency of Subcritical Water Extraction of Proteins and Amino Acids from Porcine Placenta
}

\author{
Sung Hee Park, Jae-Hyeong Kim, Sang-Gi Min, Yeon-Ji Jo*, and Ji-Yeon Chun* \\ Department of Bioindustrial Technologies, Konkuk University, Seoul 143-701, Korea
}

\begin{abstract}
In a previous study, hydrolysates of porcine placenta were obtained and the extraction efficiency for proteins and amino acids was compared between sub- and super-critical water extraction systems; optimum efficiency was found to be achieved using subcritical water $\left(170^{\circ} \mathrm{C}, 10 \mathrm{bar}\right)$. In this study, the effects of adding ethanol to the subcritical water system were investigated. The lowest-molecular-weight extraction product detected weighed $434 \mathrm{Da}$, and the efficiency of extraction for low-molecular-weight products was increased when either the concentration of ethanol was decreased, or the extraction time was lengthened from $10 \mathrm{~min}$ to $30 \mathrm{~min}$. The highest concentration of free amino acids (approximately $8 \mathrm{mM}$ ) was observed following $30 \mathrm{~min}$ extraction using pure distilled water. The concentration of free amino acids was significantly lower when ethanol was added or a shorter extraction time was used $(p<0.05)$. Color change of the solution following extraction was measured. There were no significant differences in color between lysates produced with different extraction times when using distilled water $(p>0.05)$; however, using different extraction times produced significant differences in color when using $20 \%$ or $50 \%$ ethanol solution for subcritical extraction $(p<0.05)$. The range of $\mathrm{pH}$ for the hydrolysate solutions was $6.4-7.5$. In conclusion, the investigated extraction system was successful in the extraction of $\leq 500$ Da hydrolysates from porcine placenta, but addition of ethanol did not yield higher production of low-molecular-weight hydrolysates than that achieved by DW alone.
\end{abstract}

Key words: porcine placenta, collagen peptide, subcritical water, supercritical ethanol extraction

Received October 19, 2014 / Revised March 11, 2015 / Accepted March 16, 2015

\section{Introduction}

Biologically active peptides that are able to affect numerous physiological functions can be released from dietary proteins during gastrointestinal digestion, food processing, or microbial fermentation (Gómez-Guillén et. al., 2011). Collagen obtained from various animal by-products has been focused on as a source of bioactive peptides in medicine and pharmaceuticals as well as the functional food industry, and the control of collagen metabolism might be useful for a variety of therapeutic and cosmetic applications (Kim et al., 2010; Yoshikawa et al., 2013; Zhang et al., 2006). Alemán et al. (2013) pointed out that the average molecular weight of collagen hydrolysates is one of the vital factors that determine their biological properties. Low-molecular-weight peptides possess

\footnotetext{
*Corresponding author: Ji-Yeon Chun, Department of Bioindustrial Technologies, Konkuk University, Seoul 143-701, Korea. Tel: +82-2-450-3672, 3680, Fax: +82-2-455-1044, E-mail: chunjiyeon@konkuk.ac.kr; Yeon-Ji Jo, Department of Bioindustrial Technologies, Konkuk University, Seoul 143-701, Korea. Tel: +82-2-450-3672, 3680, Fax: +82-2-455-1044, Email:whduswl86@naver.com
}

various advantageous bioactivities and functionalities, including antioxidant properties, antihypertensive/angiotensin converting enzyme inhibitory activity, antimicrobial activity, mineral binding capacity, lipid-lowering effects, and immunomodulatory activity (Gómez-Guillén et al., 2011). Collagen derived from porcine placenta is a source of various amino acids (lysine, valine, glycine, alanine, arginine etc.), B vitamins, and minerals. In a study by Han et al. (2013), the skin permeability and biological activities of porcine placenta hydrolysates extracted under subcritical conditions were determined and it was concluded that porcine placenta extracts have potential as anti-wrinkle agents due to inhibiting elastases. In concordance with Han et al.'s conclusions, Yoshikawa et al. (2014) evaluated the efficacy of porcine placental extract on reducing wrinkle widths below the eye in climacteric women and found a significant dose-dependent improvement in the placental extract treatment groups relative to the results in the untreated subjects.

Collagen-derived hydrolysates and peptides are generally obtained by treating collagen with commercial proteases including trypsin, chymotrypsin, pepsin, alcalase, properase E, pronase, collagenase, bromelain and papain 
(Gómez-Guillén et al., 2011). In a study by Kim et al. (2010), porcine placenta was treated with alkali, acid, and enzyme treatments to obtain extracts containing collagen hydrolysates. However, this procedure requires a long processing time and the resulting extraction products are not safe to consume directly without purification. In an attempt to find a solution for these problems, we previously investigated sub- and super-critical water extraction methods, which are considered to be green/eco-friendly chemical processing techniques due to using water as the solvent, for their efficiency in hydrolyzing porcine placenta collagen within a one-hour processing time, and we optimized pressure, holding times, and temperature (Lee et al., 2013).

Organic solvents such as methanol (Iqbal et al., 2005), ethanol (EtOH) (Kaneda et al., 2004), and acetone (Chung and Woo, 2001) have been used to extract the functional substances from rice bran. In a study by Chiou et al. (2012), defatted rice bran treated with aqueous EtOH under subcritical conditions showed better antioxidative capacity than a similar extract obtained by subcritical water extraction, demonstrating that EtOH combined with sub- and super-critical water treatment was able to improve the recovery efficiency of by-products from rice milling. However, there were few previous studies on the extraction of collagen from animal by-products like porcine placenta using aqueous EtOH as an organic solvent under sub- and super-critical conditions. Therefore, this study aimed to investigate the effects of adding $\mathrm{EtOH}$ to the medium used for subcritical water extraction of porcine placenta on the characteristics of the resulting hydrolysates.

\section{Materials and Methods}

\section{Hydrolysis treatment process of porcine placenta}

To prepare pre-treatment porcine placenta, frozen porcine placenta provided by SAMWOO husbandry (Korea) was thawed at $4^{\circ} \mathrm{C}$ for $12 \mathrm{~h}$. Thawed porcine placenta was rinsed with running water to remove residual blood or secretion waste. All visible fat was trimmed and the placenta was cut into $5 \mathrm{~cm}$ lengths. Finally, porcine placenta was spin-dried. And to hydrolysis of porcine placenta, a laboratory-scale subcritical water system (SFE SYSTEM, CS-1000) was collaboratively re-designed by the Laboratory of Food Engineering in Konkuk University and REXO Engineering (Korea). The system was composed of a control box, vessel (reactor), water bath, heater, temperature controller, and pressure controller (Fig. 1). Porcine placenta was mixed 1:15 (w/w) with distilled water (DW), $20 \% \mathrm{EtOH}$, or $50 \% \mathrm{EtOH}$ in the reaction vessel and then heated up to $170^{\circ} \mathrm{C}$. After reaching the target temperature, the temperature was held at $170^{\circ} \mathrm{C}$ for either $10 \mathrm{~min}$ or $30 \mathrm{~min}$ and pressure was maintained at $10 \mathrm{bar}$. The vessel was then cooled down to $40-45^{\circ} \mathrm{C}$ and pressure was decreased to 0.1 bar using a $4^{\circ} \mathrm{C}$ water bath with coolant circulation. All chemicals used in this study were analytical grade and purchased from Sigma-Aldrich Corp. (USA).

\section{Gel permeation chromatography}

Samples were centrifuged at $10,000 \mathrm{~g}$ for $5 \mathrm{~min}$ and the molecular weight of peptides in the supernatant was determined by gel permeation chromatography (GPC) based on

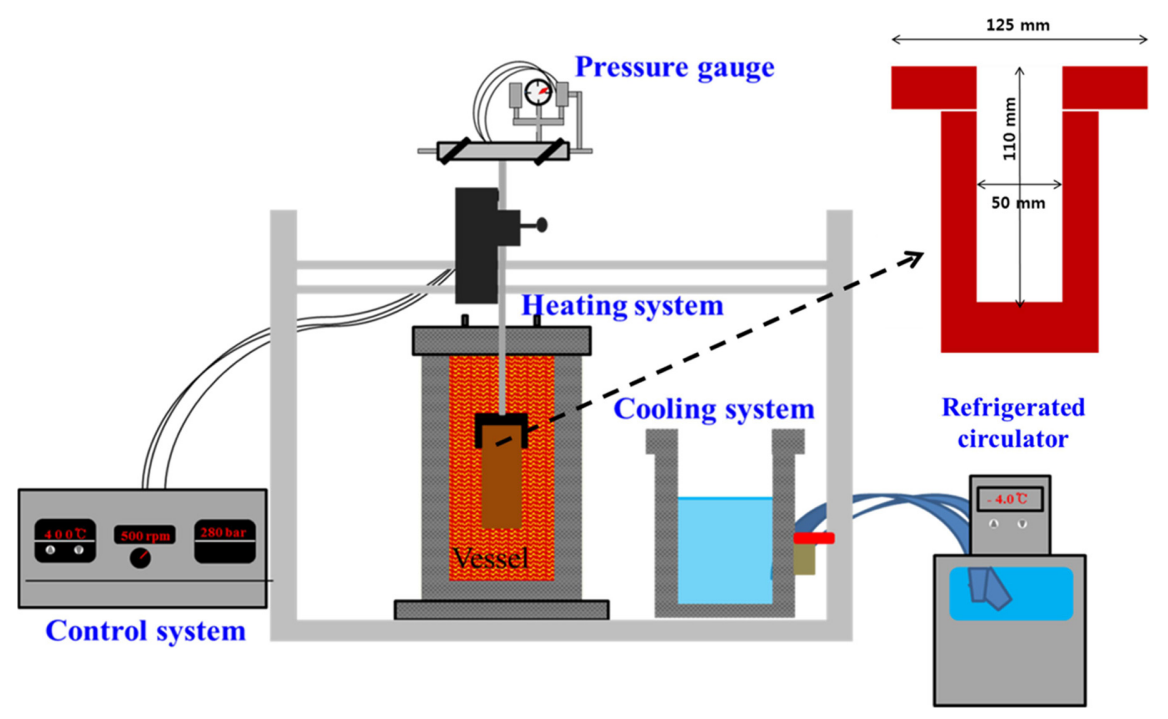

Fig. 1. Schematic diagram of the hydrolysis system apparatus. 
the method of Gu et al. (2011). A YL 9100 high performance liquid chromatography (HPLC) system (Younglin Instrument Co. Ltd., Korea) equipped with three Ultrahydrogel $^{\mathrm{TM}} 120$ columns $(7.8 \times 3,000 \mathrm{~mm}$, Waters, USA $)$ was used for GPC analysis. The flow rate of the mobile phase was $1 \mathrm{~mL} / \mathrm{min}$ using deionized/distilled water. The $\mathrm{Mw}$ distributions of the peptides were monitored using a YL 9100 refractive index detector (YL Instrument Co. Ltd., Korea) at $40^{\circ} \mathrm{C}$. A Mw standards kit $(0.68-1670 \mathrm{kDa}$, Polymer standards service, Germany) was used as reference standards.

\section{Free amino acid}

The concentration of free amino acids in the hydrolysate solutions was determined by the method of Benjakul and Morrissey (1997). Solutions were centrifuged at $1,000 \mathrm{~g}$ for $15 \mathrm{~min}$ and the supernatant was collected. The supernatant $(125 \mu \mathrm{L})$ of hydrolysates derived from porcine placenta was mixed with $2 \mathrm{~mL}$ of sodium phosphate buffer $(\mathrm{pH} 8.2,0.2152 \mathrm{M})$ and $1 \mathrm{~mL}$ of $0.01 \%(\mathrm{w} / \mathrm{v})$ 2.4.6-trinitrobenzenesulfonic acid and incubated for 30 min at $50^{\circ} \mathrm{C}$. Treated H-PS was cooled at ambient temperature and then it was reacted with $1 \mathrm{~mL}$ of $0.1 \mathrm{M}$ sodium sulfite. Absorbance of the reactant was determined at 420 $\mathrm{nm}$ by using a UV/VIS spectrophotometer. The free amino group content was expressed in terms of L-leucine (Nagarajan et al., 2012).

\section{Biuret reaction}

Protein assays based on the Biuret reaction have been used by numerous investigators. The Biuret reaction involves a reagent containing copper (cupric) ions in alkaline solution. Molecules containing 2 or more peptide bonds associate with the cupric ions to form a coordination complex that imparts a purple color to the solution with $A_{\max }=540 \mathrm{~nm}$. The purple color of the complex can be measured independently of the blue color of the reagent itself with a spectrophotometer or colorimeter. In other words, for the preparation of biuret reagent, $1.5 \mathrm{~g}$ of $\mathrm{CuSO}_{4} \cdot 5 \mathrm{H}_{2} \mathrm{O}$ and $6 \mathrm{~g}$ of $\mathrm{NaKC}_{4} \mathrm{H}_{4} \mathrm{O}_{6} 4 \mathrm{H}_{2} \mathrm{O}$ was dissolved in $500 \mathrm{~mL} \mathrm{DW}$ and $300 \mathrm{~mL}$ of $10 \% \mathrm{NaOH}$ was then added. One milliliter of sample was combined with $4 \mathrm{~mL}$ of biuret reagent and then the mixture was kept at $50^{\circ} \mathrm{C}$ for 20 min. Absorbance was determined at $540 \mathrm{~nm}$ for the mixture and a blank solution containing biuret reagent and DW only. A standard curve was produced from known concentrations of the protein bovine serum albumin (BSA), which is frequently used for this purpose.

\section{Color, pH, and moisture content}

The color of extraction products was determined using a colorimeter (Minolta Chroma meter CR-210, Japan), which was calibrated with a white standard (CIE $L^{*}=$

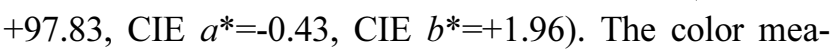
surement was performed on the surface and measured five times for each sample at different locations. The color values (CIE $L^{*}, a^{*}$, and $b^{*}$ ) were determined as indicators of lightness, redness, and yellowness, respectively. Total color difference $(E)$ was calculated using the equation:

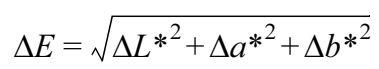

The $\mathrm{pH}$ of hydrolysates was determined using a $\mathrm{pH}$ meter (Model S220, Mettler Toledo GmbH, Greifensee, Switzerland).

\section{Results and Discussion}

\section{Molecular weight distribution of extraction prod- ucts}

Fig. 2 shows the average molecular weights of hydrolyzed porcine placenta extraction products produced with various extraction media and holding times, and Fig. 2A shows the full molecular weight spectra of extracts produced with each method variation. There were two major groups of molecular weight peaks; one group was located at over 20,100 Da and the other group near $434 \mathrm{Da}$. Although most of the higher peaks were not included in the molecular weight standards, it was clear from our observations that the extraction products were shifted to the lower molecular weight range for extractions using lower EtOH concentrations or longer holding times $(30 \mathrm{~min})$. As Fig. 2B shows, we selected peak ranges by comparison with molecular weight standards. The lowest molecular weight peaks were observed near $434 \mathrm{Da}$ in all extracts and the height of peak varied depending on medium type and holding time. Higher peaks were observed for DW (without $\mathrm{EtOH})$ and the longer holding time (30 min), while the lowest height peak was observed for $50 \% \mathrm{EtOH}$ and the shorter (10 min) holding time, indicating less efficient extraction of low-molecular-weight products under these conditions.

In our previous study (Lee et al., 2013), the placenta was treated using high pressure and high temperature processing at increasing temperatures $\left(150^{\circ} \mathrm{C}, 170^{\circ} \mathrm{C}\right.$, and 200 $\left.{ }^{\circ} \mathrm{C}, 37.5 \mathrm{MPa}\right)$ and holding times $(0,30$, and $60 \mathrm{~min})$. The results of the previous study also showed there were two groups of peaks, one over 20,100 Da and another below 


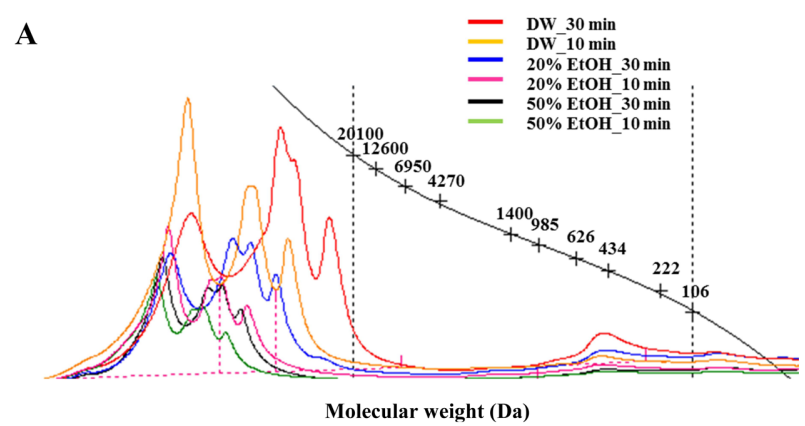

B

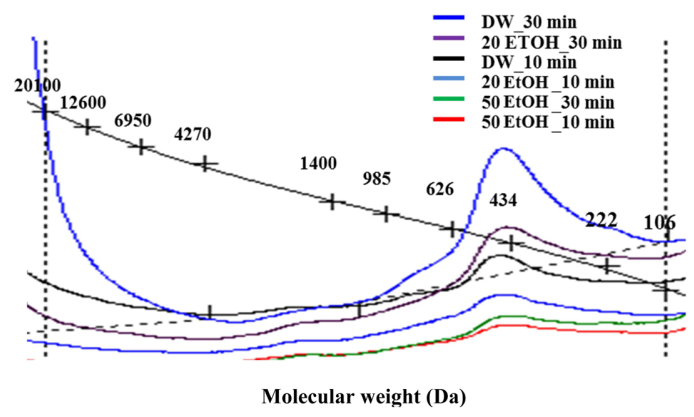

Fig. 2. Gel permeation chromatograph of porcine placenta hydrolysates produced using various extraction media and holding times, (A) full range of molecular weights (Da) (B) between 20,100 Da and 106 Da.

$106 \mathrm{Da}$. It was thought that the first group (high molecular weight) would probably represent solubilized gelatin and/or partially hydrolyzed high-molecular-weight peptides, while the second group (low molecular weight) possibly indicated small peptide hydrolysates with enhanced hydrolysis. Increasing the temperature used for extraction shifted the peak from high to low molecular weight; however, no difference was observed in the molecular weight of products of extractions with different holding times at constant temperature $\left(170^{\circ} \mathrm{C}\right)$ (Lee et al., 2013).

In this study, the lowest molecular weight peak observed was $434 \mathrm{Da}$, larger than the lowest molecular weight peak of $106 \mathrm{Da}$ detected in our previous study. The extraction temperature used was the same as that used in the previous study $\left(170^{\circ} \mathrm{C}\right)$, but the pressure was much lower at 10 bar than at 375 bar used previously (Lee et al., 2013). The addition of EtOH was not effective to improve the extraction of low-molecular-weight products, but a longer extraction time apparently improved the efficiency of porcine placenta hydrolysis.

\section{Free amino acid and crude protein contents}

Protein decomposition was determined by measuring free amino group content to evaluate the amount of complete hydrolysates obtained from porcine placenta (Fig.

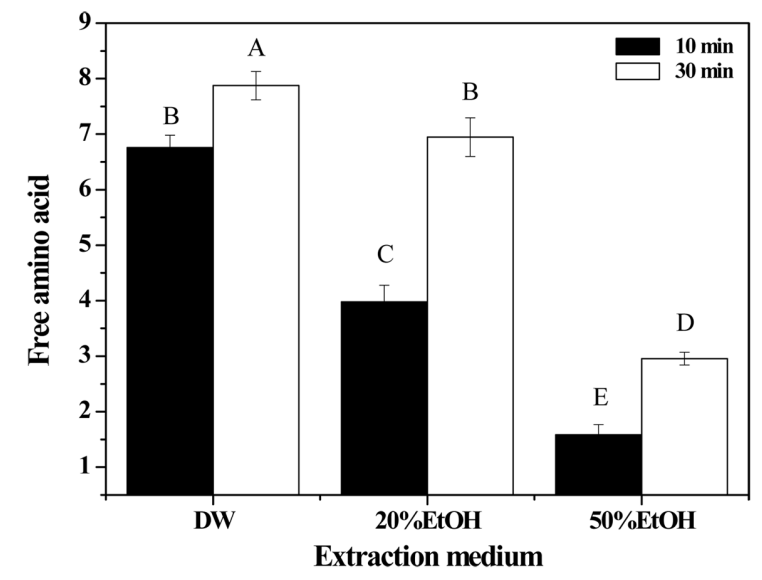

Fig. 3. Free amino acid content of porcine placenta hydrolysates produced using various extraction media and holding times.

3). It was unclear how much porcine placenta was hydrolyzed by hydrolysis processing, because the amounts of soluble gelatin and collagen hydrolysates could not be quantified (Kim et al., 2014; Lee et al., 2013). As Fig. 3 shows, the highest free amino group content of around 8 $\mathrm{mM}$ was obtained using DW only without EtOH and 30 min extraction holding time. The free amino acid content was significantly decreased when using increased $\mathrm{EtOH}$ concentrations and a shorter extraction time $(p<0.05)$. The results of our previous study, Lee et al. (2013), indicated that the main factor affecting the efficiency of porcine placenta hydrolysis by high temperature and high pressure processing was not pressure but temperature. Furthermore, the optimum condition for placenta hydrolysis was found to be $170^{\circ} \mathrm{C}$ for $30 \mathrm{~min}$. In a study by Nagarajan et al. (2012), squid skin was hydrolyzed by various extraction temperatures $\left(50-80^{\circ} \mathrm{C}\right)$ and the free amino group content was increased as the extraction temperature was increased. It was supposed that the free amino group content (which indicates protein decomposition) might be mainly influenced by the extraction temperature in the studies by Lee et al. (2013) and Nagarajan et al. (2012), and the findings of this study concur with the previous results.

Crude protein content (\%) was highest for extractions performed using $20 \%$ EtOH medium and 30 min extraction time, followed by $50 \%$ EtOH medium and same extraction time (Fig. 4). These results were the inverse of those for free amino acid content. Although a high concentration of crude protein was detected in the products from the extractions with EtOH and DW mixtures, the protein was not hydrolyzed to amino acids. These two 


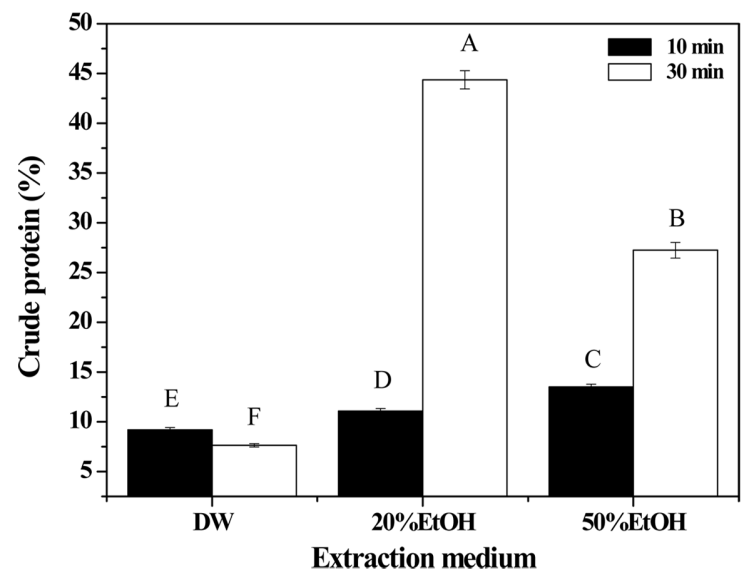

Fig. 4. Crude protein content of porcine placenta hydrolysates produced using various extraction media and holding times.

results for free amino acid and crude protein concentration also showed that EtOH and DW mixtures were not effective for the extraction or hydrolysis of porcine placenta. Moreover, the results of the molecular weight distribution analysis (Fig. 2) also supported this conclusion.

Addition of EtOH was less effective than DW alone for the hydrolysis porcine placenta, since EtOH addition resulted in low free amino acids in the extraction products, (Fig. 3) and the products of extractions with $\mathrm{EtOH}$ had larger average molecular weights (Fig. 2). However, it was observed that a longer extraction time (30 min rather than $10 \mathrm{~min}$ ) apparently improved the efficiency of porcine placenta hydrolysis, either with or without addition of EtOH to the extraction medium. As described previously many times, the hydrogen bonds of water are broken under supercritical or subcritical conditions and under those conditions, the water becomes less polar and has properties more like an organic solvent such as $\mathrm{EtOH}$ or methanol. Therefore, the solubility of organic materials could be increased by sub- or supercritical water (Brunner, 2014; Sasaki, 1998; Savage, 1999). In our extraction system, it can be expected that the vapor pressure of water could not reach the effective range for extraction or hydrolysis of protein, because the vapor pressure of $\mathrm{EtOH}$ is higher than water at the same temperature. Moreover, EtOH has been used more for extraction of functional substances from vegetable materials than for precipitation of proteins after hydrolyzing animal or vegetable materials (Lee, 2010; Yeom, 2010).

\section{Color and pH}

The color of porcine placenta was determined before
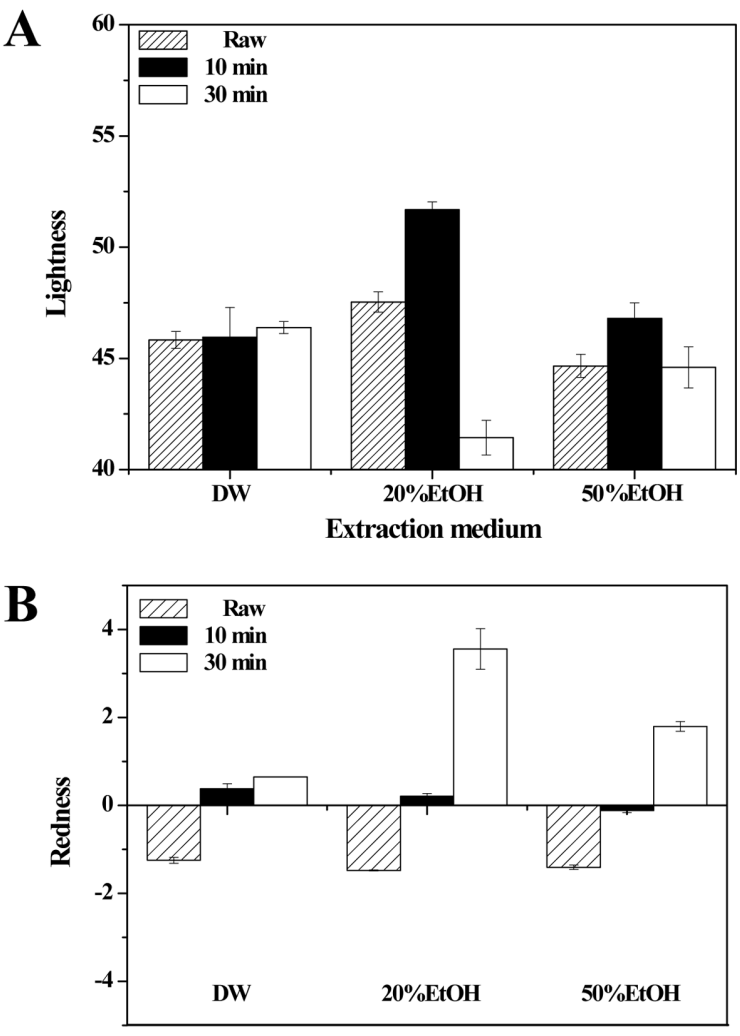

Extraction medium

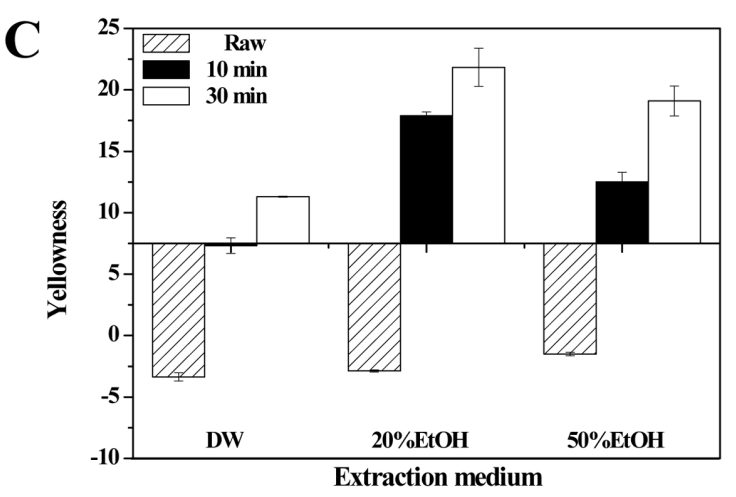

Fig. 5. Color of porcine placenta hydrolysates produced using various extraction media and holding times. (A) Lightness, (B) Redness, (C) Yellowness.

and after hydrolysis (Figs. 5 and 6). As Fig. 5 shows, there was no significant difference between extraction times for DW alone ( $p>0.05$ ), but with the addition of $20 \%$ or $50 \%$ $\mathrm{EtOH}$, differences in color were observed between different extraction times. Interestingly, 10 min extraction made the sample brighter, but the sample was darker at $30 \mathrm{~min}$ extraction $(p<0.05)$. For the colorimetric parameters of redness and yellowness, there were significant differences between baseline color and color following extraction in all types of media $(p<0.05)$. Especially, 20\% EtOH medium produced a greater color change than other media did. 


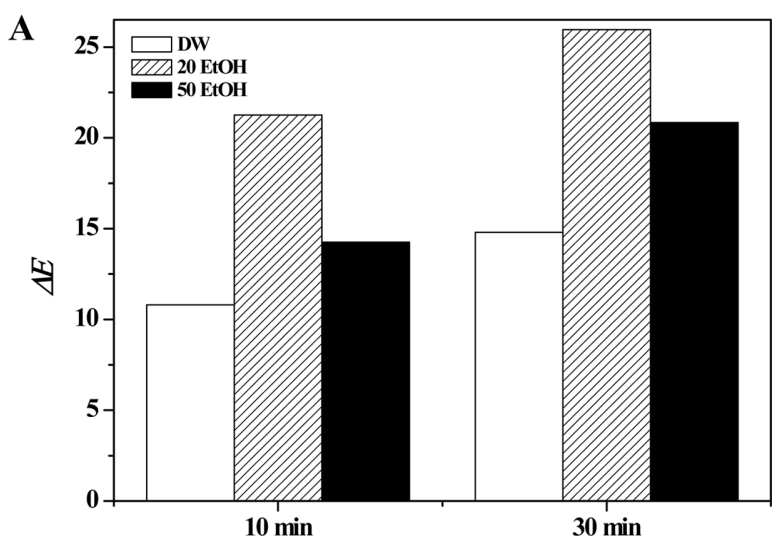

Extraction time

B

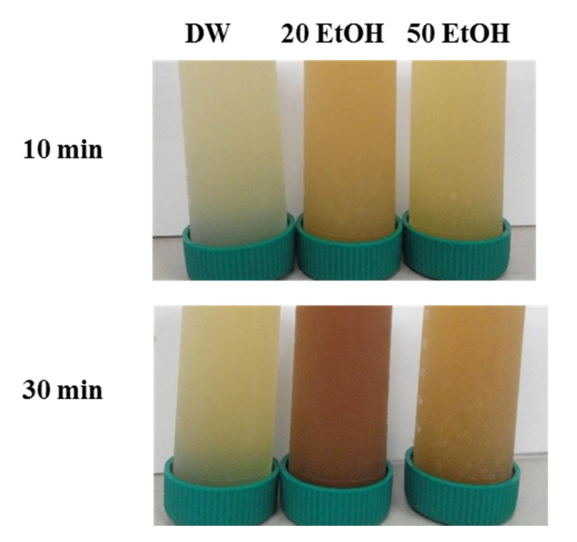

Fig. 6. Total color difference (A) and photographic images of porcine placenta hydrolysates produced using various extraction media and holding times.

Total color difference of all samples was calculated (Fig. 6A). In the CIE $1976\left(L^{*}, a^{*}, b^{*}\right)$ color space, the total color difference of all the samples was dramatically higher than that in raw porcine placenta, and it increased slightly with increased extraction time. As expected, total color difference was highest at $20 \%$ EtOH medium. Photographic images of samples were taken to show the visually apparently differences in color between samples (Fig. 6B).

The $\mathrm{pH}$ of porcine placenta was slightly decreased with longer extraction times and $\mathrm{pH}$ was higher following 50\% EtOH extraction than for other media, but it did not reach the alkaline range $(\mathrm{pH}>9.0)$ (Fig. 7). The range of $\mathrm{pH}$ for the various extraction products was 6.4-7.5, similar to that of pure water. Self-ionization of water generates increase of $\left[\mathrm{OH}^{-}\right]$by temperature and pressure, leading to increased pH (Brunner, 2009, 2014; Penninger et al., 2000; Ravber et al., 2015; Watchararuji et al., 2008). In a previous study (Kim et al., 2014), self-ionization was observed in sub-critical water or super-critical water extraction systems that led to an increase in the $\mathrm{pH}$ of porcine skin

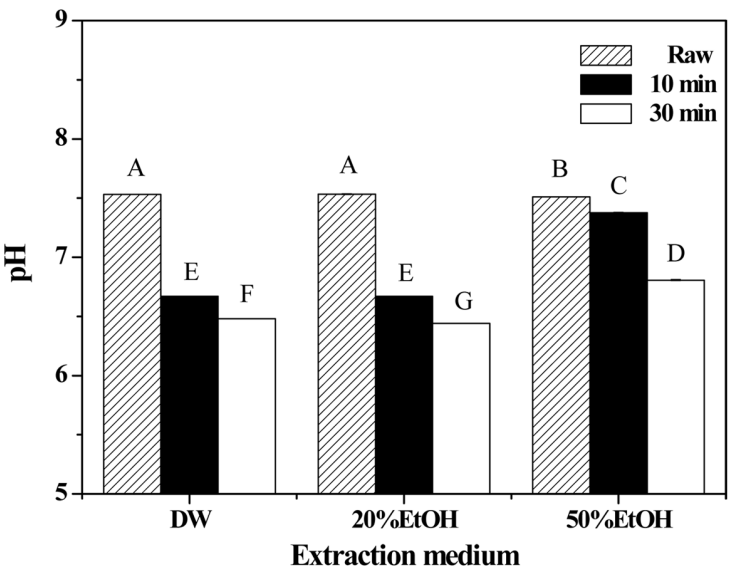

Fig. 7. pH of porcine placenta hydrolysates produced using various extraction media and holding times.

from 7.29 (Raw) to 9.22 (sub-critical water, $300^{\circ} \mathrm{C}$ and 80 bar) and 9.49 (super-critical water, $400^{\circ} \mathrm{C}$ and 280 bar). Similarly, in a study by Alargov et al. (2002), the pH of glycine was changed from 6.4 to 8.0 incrementally according to the increasing temperature of water under superand subcritical conditions $\left(300-400^{\circ} \mathrm{C}\right.$ and $\left.22.2-40 \mathrm{MPa}\right)$. Moreover, when glycine is decomposed at high temperature (e.g., melting point $233^{\circ} \mathrm{C}$ ), the $\mathrm{pH}$ of the reaction mixture is increased by the formation of methylamine and other amines (Sato et al., 2002). It assumed that there was no self-ionization in the extraction conditions used in this study, likely because the hydrolysis temperatures used in this study were more than $100^{\circ} \mathrm{C}$ lower, than that used the other studies discussed above (Alargov et al., 2002; Kim et al., 2014; Sato et al., 2002).

\section{Conclusions}

Hydrolyzed porcine placenta was produced by using subcritical water with the addition of $20 \%$ or $50 \% \mathrm{EtOH}$. Using this subcritical extraction system $\left(170^{\circ} \mathrm{C}, 10\right.$ bar $)$, hydrolysates with molecular mass less than $500 \mathrm{Da}(434$ Da) were successfully extracted from porcine placenta, but the addition of EtOH did not yield better extraction efficiency for lower-molecular-weight hydrolysates than that achieved using DW alone. In other words, low-molecular-weight hydrolysates were extracted from porcine placenta with or without EtOH. Namely, it was also observed that DW was the more effective extraction medium for hydrolyzing porcine placenta under subcritical conditions. Although subcritical EtOH extraction is not an efficient technique for porcine placenta in this study, this subcritical extraction system was confirmed as an effective 
hydrolysis method. And it could be possible to apply this methodology to the extraction of bioactive substances from other materials such as herb or plants in future studies.

\section{Acknowledgements}

Financial support for this study was obtained from the Korean Institute of Planning and Evaluation for Technology in Food, Agriculture, Forest, and Fisheries, Korea (iPET Project No. 311029-3). This paper was supported by the KU Research Professor Program of Konkuk University.

\section{References}

1. Alargov, D. K., Deguchi, S., Tsujii, K., and Horikoshi, K. (2002) Reaction behaviors of glycine under super- and subcritical water conditions. Orig. Life Evol. Biosph. 32, 1-12.

2. Alemán, A., Gómez-Guillén, M. C., and Montero, P. (2013) Identification of ace-inhibitory peptides from squid skin collagen after in vitro gastrointestinal digestion. Food Res. Int. 54, 790-795.

3. Benjakul, S. and Morrissey, M. T. (1997) Protein hydrolysates from pacific whiting solid wastes. J. Agric. Food Chem. 45, 3423-3430.

4. Brunner, G. (2009) Near critical and supercritical water. Part I. Hydrolytic and hydrothermal processes. J. Supercritical Fluid 47, 373-381.

5. Brunner, G. (2014) Supercritical fluid science and technology. In: Hydrothermal and supercritical water processes. Brunner, G. (ed) Elsevier B.V, 5, pp. 9-93.

6. Chiou, T. Y., Neoh, T. L., Kobayashi, T., and Adachi, S. (2012) Properties of extract obtained from defatted rice bran by extraction with aqueous ethanol under subcritical conditions. Food Sci. Technol. Res. 18, 37-45.

7. Chung, H. S., and Woo, W. S. (2001) A quinolone alkaloid with antioxidant activity from the aleurone layer of anthocyanin-pigmented rice. J. Nat. Prod. 64, 1579-1580.

8. Gu, R. Z., Li, C. Y., Liu, W. Y., Yi, W. X., and Cai, M. Y. (2011) Angiotensin I-converting enzyme inhibitory activity of low-molecular-weight peptides from Atlantic salmon (Salmosalar L.) skin. Food Res. Int. 44, 1536-1540.

9. Gómez-Guillén, M. C., Giménez, B., López-Caballero, M. E., and Montero, M. P. (2011) Functional and bioactive properties of collagen and gelatin from alternative sources: A review. Food Hydrocolloids 25, 1813-1827.

10. Han, J. H., Kim, M. R., Park, Y. H., Hong, Y. H. and Suh, H. J. (2013) Skin permeability of porcine placenta extracts and its physiological activities. Korean J. Food Sci. An. 33, 356362.

11. Iqbal, S., Bhanger, M. I., and Anwar, F. (2005) Antioxidant properties and components of some commercially available varieties of rice bran in Pakistan. Food Chem. 93, 265-272.

12. Kaneda, I., Iwai, K., Kubo, H., and Sakurai, H. (2004) Antioxidative properties of extracts from ancient rice brans. Food
Sci. Technol. Res. 10, 374-382.

13. Kim, B. Y., Kim, T., Kang, W. Y., Hyun, B., Cheon, H. Y., and Kim, D. (2010) Functional cosmetic effect of porcine placenta. Korean Chem. Eng. Res. 48, 327-331.

14. Kim, J. H., Jeong, K. H., Shim, J. B., Jeong, Y. K., Jang, M. Y., Jo, Y. J., Min, S. G., and Chun, J. Y. (2014) Effect of superor sub-critical water treatment on physicochemical properties of pig skin. P 13-033, 2014 Annual Meeting of Korean Society of food Sci. and Technol., Gwangju, Korea, pp. 164-165.

15. Lee, H. Y. (2010) Development of multicomplex extraction and nano-encapsulation processes for improving immune activation and anti-aging activities of medicinal plants, Research project supported by Rural Development Administration, Kangwon Univ. ChunCheon, Korea.

16. Lee, M. Y., Choi, Y. C., Chun, J. Y., Min, S. G., and Hong, G. P. (2013) Effects of high pressure/high temperature processing on the recovery and characteristics of porcine placenta hydrolysayes. Korean J. Food Sci. An. 33, 474-480.

17. Nagarajan, M., Benjakul, S., Prodpran, T., Songtipya, P., and Kishimura, H. (2012) Characteristics and functional properties of gelatin from splendid squid (loligo formosana) skin as affected by extraction temperatures. Food Hydrocolloid. 29, 389-397.

18. Penninger, J. M. L., Kersten, R. J. A. and Baur, H. C. L. (2000) Hydrolysis of diphenylether in supercritical water: Effects of dissolved NaCl. J. Supercrit. Fluids 17, 215-226.

19. Ravber, M., Knez, Ž., and Škerget, M. (2015) Simultaneous extraction of oil- and water-soluble phase from sunflower seeds with subcritical water. Food Chem. 166, 316-323.

20. Sato, N., Daimon, H., and Fujie, K. (2002) Decomposition of glycine in high temperature and high pressure water. Kag. Kog. Ronbunshu. 28, 113-117.

21. Sasaki, M., Kabyemela, B., Malaluan, R., Hirose, S., Takeda, N., Adschiri, T., and Arai, K. (1998) Cellulose hydrolysis in subcritical and supercritical water. J. Supercrit. Fluids 13, 261-268.

22. Savage, P. E. (1999) Organic chemical reactions in supercritical water. Chem. Rev. 99, 603-622.

23. Watchararuji, K., Goto, M., Sasaki, M., and Shotiprunk, A. (2008) Value-added subcritical water hydrolysate from rice bran and soybean meal. Bioresour. Technol. 99, 6207-6213.

24. Yoshikawa, C., Koike, K., Takano, F., Sugiur, K., and Suzuki, N. (2014) Efficacy of porcine placental extract on wrinkle widths below the eye in climacteric women. Climacteric. $\mathbf{4}$, 370-376

25. Yoshikawa, C., Takano, F., Ishigaki, Y., Okada1, M., Kyo, S., Suzuki, N., Sugiura, K., and Koike, K. (2013) Effect of porcine placental extract on collagen production in human skin fibroblasts In Vitro. Gynecol. Obstet. 3, 1000186.

26. Yeom, H. J., Lee, E. H., Ha, M. S., Ha, S. D., and Bae, D. H. (2010) Production and physicochemical properties of rice bran protein isolates prepared with autoclaving and enzymatic hydrolysis. J. Korean Soc. Appl. Biol. Chem. 53, 62-70.

27. Zhang, Z., Li, G., and Shi, B. (2006) Physicochemical properties of collagen, gelatin and collagen hydrolysate derived from bovine limed split wastes. J. Society Leather Technol. Chem. 90, 23-28. 